\title{
Calibration and intercomparison of acetic acid measurements using proton-transfer-reaction mass spectrometry (PTR-MS)
}

\author{
K. B. Haase ${ }^{1,2}$, W. C. Keene ${ }^{3}$, A. A. P. Pszenny ${ }^{1}$, H. R. Mayne $^{4}$, R. W. Talbot ${ }^{1,5}$, and B. C. Sive ${ }^{1,6}$ \\ ${ }^{1}$ Institute for the Study of Earth, Oceans, and Space, Morse Hall, 8 College Road, The University of New Hampshire, \\ Durham NH 03824, USA \\ ${ }^{2}$ Presently at the US Geological Survey, National Center, 12201 Sunrise Valley Dr., MS 432, Reston VA 20192, USA \\ ${ }^{3}$ Department of Environmental Sciences, Clark Hall, 291 McCormick Road, PO Box 400123, University of Virginia, \\ Charlottesville VA 22904, USA \\ ${ }^{4}$ Department of Chemistry, Parsons Hall, 23 Academic Way, The University of New Hampshire, Durham NH 03824, USA \\ ${ }^{5}$ Department of Earth \& Atmospheric Sciences, 4800 Calhoun Road, The University of Houston, Houston TX 77204, USA \\ ${ }^{6}$ Department of Chemistry, Appalachian State University, Boone NC 28608, USA
}

Correspondence to: K. B. Haase (khaase@usgs.gov)

Received: 25 May 2012 - Published in Atmos. Meas. Tech. Discuss.: 4 July 2012

Revised: 16 October 2012 - Accepted: 21 October 2012 - Published: 15 November 2012

\begin{abstract}
Acetic acid is one of the most abundant organic acids in the ambient atmosphere, with maximum mixing ratios reaching into the tens of parts per billion by volume (ppbv) range. The identities and associated magnitudes of the major sources and sinks for acetic acid are poorly characterized, due in part to the limitations of available measurement techniques. This paper demonstrates that, when properly calibrated, proton-transfer-reaction mass spectrometry (PTR-MS) can be a valuable technique for fast response, accurate quantification of acetic acid in ambient air. Three different PTR-MS configurations were calibrated at low ppbv mixing ratios using permeation tubes, which yielded calibration factors between 7.0 and 10.9 normalized counts per second per ppbv (ncps ppbv ${ }^{-1}$ ) at a drift tube field strength of 132 Townsend (Td). Detection limits ranged from 0.06 to $0.32 \mathrm{ppbv}$ with dwell times of $5 \mathrm{~s}$. These calibration factors showed negligible humidity dependence. Acetic acid was measured with PTR-MS on Appledore B Island, ME, during the International Consortium for Atmospheric Research on Transport and Transformation (ICARTT) campaign and validated based on acetic acid measured in parallel using tandem mist chambers coupled with ion chromatography (MC/IC). Mixing ratios ranged from a minimum of $0.075 \pm 0.004 \mathrm{ppbv}$ to $3.555 \pm 0.171 \mathrm{ppbv}$, with a median mixing ratio of $0.530 \pm 0.025 \mathrm{ppbv}$. An orthogonal least squares linear regression of paired data yielded a slope
\end{abstract}

of $1.14 \pm 0.06(2 \sigma)$, an intercept of $0.049 \pm 0.020(2 \sigma) \mathrm{ppbv}$, and an $R^{2}$ of 0.78 .

\section{Introduction}

Acetic acid $\left(\mathrm{CH}_{3} \mathrm{COOH}\right)$ is among the most dominant organic acids in the troposphere, with maximum mixing ratios in the range of tens of parts per billion (ppbv). Acetic acid influences the acidity of precipitation, cloud water and atmospheric aerosols and thereby modulates $\mathrm{pH}$-dependent chemical processes in the atmosphere (Meng et al., 1995). Primary sources include direct emissions from industrial processes, biomass combustion, vegetation, and soils (Chebbi and Carlier, 1996; Talbot et al., 1999; Kesselmeier, 2001). Acetic acid is also produced in the atmosphere from the oxidation of alkenes by ozone and hydroxyl radical, and through acetylperoxy-hydroperoxy reactions (Niki et al., 1985; Orzechowska and Paulson, 2005; Lee et al., 2006b; Yu et al., 2008; Paulot et al., 2011). The primary atmospheric sinks for acetic acid are dry and wet deposition, with estimated lifetimes ranging from several hours to several days depending on deposition conditions (Chebbi and Carlier, 1996; Grosjean and Grosjean, 1999; Rosado-Reyes and Francisco, 2006). Estimated global emissions of acetic acid are estimated to be between 1217 and $1550 \mathrm{Gmol} \mathrm{yr}^{-1}$ (von 
Kuhlmann et al., 2003; Ito et al., 2007; Paulot et al., 2011), while estimated sinks are estimated to be $\sim 1426 \mathrm{Gmol} \mathrm{yr}^{-1}$ (Paulot et al., 2011). The temporal and special variability in sources and sinks need further constraint, as measurements exceed model predictions in many situations (Paulot et al., 2011).

Proton-transfer-reaction mass spectrometry (PTR-MS) has emerged as a valuable tool for measuring volatile organic compounds (VOCs) in the ambient atmosphere. Requiring only power and a small amount of ultra-pure water for operation, PTR-MS instruments achieve parts-per-trillion by volume (pptv) limits of detection and fast response for a wide range of atmospherically relevant VOCs (Hansel et al., 1995; de Gouw and Warneke, 2006; Blake et al., 2009). The high speed and sensitivity of the PTR-MS make it an appealing tool to measure acetic acid, since its high measurement speed, commercial availability, and online analysis are favorable compared to other techniques that provide lower time resolution and require significant analyst effort. Additionally, PTR-MS allows trace gas mixing ratios to be estimated using proton transfer reaction kinetics, yielding quantitative measurement (albeit with a margin of error because of uncertainties in fragmentation and instrumental losses) of compounds that lack calibration standards (Cappellin et al., 2012). However, the only metrics by which compounds are identified via PTR-MS are the proton affinity of a target compound, which must be greater than that of water $\left(>692 \mathrm{~kJ} \mathrm{~mol}^{-1}\right)$, and the mass-to-charge ratio $(\mathrm{m} / \mathrm{z})$ of the protonated target compound, which is measured by the mass spectrometer. The majority of PTR-MS instruments currently in use possess quadrupole mass analyzers and are limited to unit mass resolution. This limitation makes it possible for isobaric protonated molecules and ion fragments to convolute the signal at a specific $m / z$, leading to inaccuracies in the compound quantification. Therefore, it is important to compare compounds measured by PTR-MS with those from an independent technique to ensure that the signal at a specific $\mathrm{m} / \mathrm{z}$ is characteristic of a target compound. For many VOCs, PTR-MS performance has been verified via paired measurements using gas chromatographic (GC) techniques in several different studies (de Gouw et al., 2003; Warneke et al., 2003; Ambrose et al., 2010; Jardine et al., 2010), but there are few comparisons for ambient measurement of acetic acid, and more are needed (de Gouw et al., 2003).

Acetic acid measurements can be subject to signal artifacts due to production and loss from various sampling media. It readily adsorbs to inlets and transfer lines, often resulting in a negative measurement bias. In particular, filter and resin measurements have proven to be problematic with artifacts and non-quantitative trapping (Keene et al., 1989). Although generally quantitative, mist chamber techniques require relatively long sampling times (typically greater than $1 \mathrm{~h}$ ) and a supply of ultrapure water, which constrains their suitability for continuous measurements over extended time periods (Keene et al., 1989). In contrast, the PTR-MS does not re- quire large quantities of consumables, and directly samples the air stream, making it a valuable tool for continuous longterm measurements.

The rate constant for the acetic acid reaction with the PTR-MS primary reagent ion $\left(\mathrm{H}_{3} \mathrm{O}^{+}\right)$is $3.0 \times 10^{-9} \mathrm{~cm}^{3}$ molec $^{-1} \mathrm{~s}^{-1}$, with a corresponding proton affinity of $784 \pm 8 \mathrm{~kJ} \mathrm{~mol}^{-1}$ (Mackay et al., 1978). Protonated acetic acid $\left(\mathrm{CH}_{3} \mathrm{COOH}\right) \mathrm{H}^{+}$is measured at $m / z 61$ in the PTRMS mass spectrum and can undergo dehydration to produce acylium ions $\left(\mathrm{CH}_{3} \mathrm{CO}^{+}\right.$at $\left.m / z 43\right)$ inside the PTR-MS drift tube. It has been shown that this dehydration pathway is disfavored (endothermic by $113.7 \mathrm{~kJ} \mathrm{~mol}^{-1}$ ) at ambient temperatures, but the likelihood increases with temperature, and is also dependent on the field strength of the drift tube (Mackay et al., 1978; Lindinger et al., 1998a). At very high field strengths ( $\geq 200 \mathrm{Td}, 1 \mathrm{Td}=10^{-17} \mathrm{~V} \mathrm{~cm}^{2}$ ), another fragment appears at $m / z 15$, the methyl cation $\mathrm{CH}_{3}^{+}$(Lindinger et al., 1998b). Several other conceivable atmospheric compounds can contribute to these mass channels. Compounds that can form a signal at $m / z 61$ include glycolaldehyde and propanols, while peroxyacetic acid and ethyl acetate form fragments that interfere at $m / z 61$ (Warneke et al., 1996; Spanel et al., 2003; de Gouw and Warneke, 2006; Rogers et al., 2006; Wyche et al., 2009; Schwarz et al., 2009; Blake et al., 2009). Many compounds may also fragment to give an ion at $m / z 43$, including fragment ions from acetaldehyde, propanols, butanal, peroxyacetyl nitrates (PANs), and ethyl acetate (Warneke et al., 1996; Steinbacher et al., 2004; de Gouw and Warneke, 2006; Rogers et al., 2006). However, many of these compounds typically are not present at high mixing ratios in the rural troposphere, and are thus not a source of significant interference (de Gouw et al., 2003; Karl et al., 2004; Steinbacher et al., 2004; Steeghs et al., 2004; Karl et al., 2005; Lee et al., 2006b; Holzinger et al., 2007; Maleknia et al., 2007; Yu et al., 2008; Fortner et al., 2009; Wyche et al., 2009; Kim et al., 2010).

Although acetic acid has been measured previously via PTR-MS and related MS techniques (Lindinger et al., 1998b; Holzinger et al., 2000; Williams et al., 2001; Warneke et al., 2004; Karl et al., 2004, 2005; Jobson et al., 2005; Sellegri et al., 2005; de Gouw et al., 2006; Feilberg et al., 2010), few studies report results based on direct instrumental calibration. Lee et al. (2006b) calibrated their instrument by diluting pure acetic acid into a Teflon bag with purified air. Wyche et al. (2009) used a permeation tube to calibrate their chemical ionization reaction time-of-flight mass spectrometer (CIR-TOF-MS). Warneke et al. $(1996,2001)$ used uncertified permeation tubes to generate gas phase acetic acid to characterize fragmentation and humidity dependence, but did not generate a calibration factor. Recently, Feilberg et al. (2010) used a permeation source to calibrate and explore the humidity dependence of their instrument for measuring emissions from livestock. Additionally, there have been several promising comparisons of acetic acid measurements using PTR-MS and other techniques. de Gouw et al. (2003) 
Table 1. A summary of acetic acid calibrations reported in the literature and in this study.

\begin{tabular}{|c|c|c|c|c|c|c|c|c|}
\hline Reference & PTR Method & $\begin{array}{c}\text { Pressure } \\
\text { (mbar) }\end{array}$ & $\begin{array}{l}\text { Temp. } \\
\left({ }^{\circ} \mathrm{C}\right)\end{array}$ & $\begin{array}{l}\text { V Drift } \\
\text { (volts) }\end{array}$ & $E / N(\mathrm{Td})$ & $\begin{array}{l}\text { Calibration } \\
\text { Method }^{\mathrm{a}}\end{array}$ & $\begin{array}{l}\text { Calibration Factor } \\
\left(\text { ncps ppbv }{ }^{-1}\right)^{\mathrm{b}}\end{array}$ & $\begin{array}{c}\text { Ratio } \\
m / z 61 / 43\end{array}$ \\
\hline Warneke et al. (1996) & PTR-MS (SS) & N/A & N/A & N/A & $\sim 120$ & N/A & N/A & 5.7 \\
\hline de Gouw et al. (2003) & PTR-MS (SS) & 2.4 & 23 & 700 & $\sim 120$ & ID & $8 \pm 0.4$ & N/A \\
\hline Christian et al. (2004) & PTR-MS (SS) & 2.0 & N/A & 600 & 130 & N/A & N/A & 2.3 \\
\hline Hartungen et al. (2004) & PTR-MS (SS) & 2.0 & 60 & 600 & 138 & N/A & N/A & 0.9 \\
\hline Lee et al. (2006a) & PTR-MS (HS) & 2 & N/A & 600 & 120 & TB & N/A & N/A \\
\hline Maleknia et al. (2007) & PTR-MS (HS) & $1.8-2.2$ & $60-30$ & $580^{\mathrm{c}}$ & 110 & HS & $\mathrm{N} / \mathrm{A}$ & 0.04 \\
\hline Wyche et al. (2009) & CIR-TOF-MS & $6-9$ & 40 & Variable $^{\mathrm{d}}$ & $\begin{array}{c}90 \\
140\end{array}$ & PT & $\begin{array}{l}45.95 \pm 1.38(\text { Low } E / N) \\
17.42 \pm 0.52(\operatorname{High} E / N)\end{array}$ & $\begin{array}{l}5.9 \\
7.6\end{array}$ \\
\hline Feilberg et al. (2010) & PTR-MS (HS) & $2.1-2.2$ & 60 & 600 & 135 & PT & N/A & $\begin{array}{l}2.3(0 \% \mathrm{RH})- \\
0.9(80 \% \mathrm{RH})\end{array}$ \\
\hline This work & PTR-MS-1 (SS) & 2.0 & 45 & 600 & 132 & PT & $7.0 \pm 0.3$ & 0.9 \\
\hline This work & PTR-MS-1 (SS) & 2.0 & 45 & 600 & 132 & $\mathrm{PT}^{\mathrm{e}}$ & $6.9 \pm 0.3$ & 1.05 \\
\hline This work & PTR-MS-2 (HS) & 2.0 & 45 & 600 & 132 & PT & $8.5 \pm 0.4$ & 1.5 \\
\hline This work & PTR-MS-1 (HS) & 2.0 & 45 & 600 & 132 & PT & $10.9 \pm 0.7$ & 1.9 \\
\hline This work & PTR-MS-1 (HS) & 2.0 & 45 & 530 & 116 & PT & $14.3 \pm 0.8$ & 2.9 \\
\hline This work & PTR-MS-1 (HS) & 2.0 & 45 & 481 & 106 & PT & $17.9 \pm 1.1$ & 3.7 \\
\hline This work & PTR-MS-1 (HS) & 2.0 & 45 & 433 & 95 & PT & $23.0 \pm 1.7$ & 4.5 \\
\hline This work & PTR-MS-1 (HS) & 2.0 & 45 & 400 & 88 & PT & $30.8 \pm 2.6$ & 6.0 \\
\hline
\end{tabular}

N/A indicates data not available

a ID: Indirect, TB: Teflon Bag, HS: Head Space: PT: Permeation Tube.

b Signal at $m / z 61$, normalized to a primary ion signal of $1 \times 10^{6}$.

c Inferred from reported values.

${ }^{\mathrm{d}} E / N$ varied along the length of the drift tube, and the instrument operated in low and high $E / N$ modes.

${ }^{\mathrm{e}} \mathrm{H}_{2} \mathrm{O}$ scrubbed from sample.

used an indirect calibration by referencing the PTR-MS signal to mist chamber data. Christian et al. (2004) compared several analytical techniques for measuring biomass burning emissions and found that correcting the signal at $m / z 61$ for acetic acid fragmentation gave good agreement with open path FTIR (Fourier Transform Infrared Spectroscopy) measurements (PTR-MS/FTIR $=1.17 \pm 0.34$ ). Previously published calibration details, along with the results from this study, are summarized in Table 1.

This work provides the first in-depth discussion on calibrating PTR-MS instruments for atmospheric acetic acid measurements. Moreover, the PTR-MS is compared with a well-established measurement technique to validate its use for acetic acid. Finally, the atmospheric relevance of the acetic acid measurements made with a PTR-MS during the International Consortium for Atmospheric Research on Transport and Transformation (ICARTT) campaign is examined (Fehsenfeld et al., 2006).

\section{Experimental}

\subsection{Instrument configuration}

Two different PTR-MS instruments (Ionicon Analytik) were employed during the acetic acid calibration study. The first instrument (PTR-MS-1 (SS)) was initially configured as a standard sensitivity model. The second instrument (PTRMS-2 (HS)) was a high sensitivity model, which features an additional intermediate vacuum stage between the drift tube and the quadrupole mass spectrometer. PTR-MS-1 (SS) was subsequently upgraded to the high sensitivity configuration (PTR-MS-1 (HS)) using a conversion kit supplied by the manufacturer (de Gouw and Warneke, 2006). The main difference between the standard sensitivity and the high sensitivity configuration is the addition of a second turbo pump, which provides additional pumping capacity in the detection region of the PTR-MS. In addition to the high sensitivity upgrade, PTR-MS-1 (HS) was further modified to reduce the amount of water vapor entering the drift tube from the ion source. By changing the position of vacuum fittings and rotating the ion source $120^{\circ}$, it was possible to replace the original 32-cm-long, $0.62 \mathrm{~cm}\left(1 / 4^{\prime \prime}\right.$ inch) outer diameter Teflon tube that links the skimmer region to the turbo pump with a $10-\mathrm{cm}$-long tube, shortening the flow path to $15 \mathrm{~cm}$ from the original $47 \mathrm{~cm}$. As a result, the pumping capacity of the skimmer region was increased, causing more water vapor to exit the ion source through the skimmer instead of through the drift tube. By reducing the amount of water entering the drift tube, the probability of reverse proton transfer reactions to water molecules from ionized compounds was reduced, thereby increasing the response to compounds with a proton affinity close to that of water. This modification was similar to that described elsewhere (Wisthaler et al., 2008; Vlasenko et al., 2010) and was not done to specifically enhance the performance of PTR-MS-1 (HS) for acetic acid measurement.

All instruments were set to an ion source water flow rate of $11 \mathrm{~cm}^{3} \mathrm{~min}^{-1}$ and a discharge current of $8 \mathrm{~mA}$. The drift tube was set to a pressure of $2.0 \mathrm{mbar}$, a temperature of $45^{\circ} \mathrm{C}$, and 
Table 2. Average \pm standard deviation of the primary ion signal for protonated clusters in the primary in PTR-MS configurations used for this study.

\begin{tabular}{lrlll}
\hline Instrument & $E / N(\mathrm{Td})$ & $\begin{array}{l}\mathrm{H}_{3} \mathrm{O}^{+} \\
(m / z 19) \\
(\mathrm{Mhz} \pm 1 \sigma)\end{array}$ & $\begin{array}{l}\mathrm{H}_{3} \mathrm{O}^{+}\left(\mathrm{H}_{2} \mathrm{O}\right) \\
(\mathrm{m} / z 37) \\
(\mathrm{hz} \pm 1 \sigma) \times 10^{4}\end{array}$ & $\begin{array}{l}\mathrm{H}_{3} \mathrm{O}^{+}\left(\mathrm{H}_{2} \mathrm{O}\right)_{2} \\
(\mathrm{~m} / z 55) \\
(\mathrm{hz} \pm 1 \sigma)\end{array}$ \\
\hline PTR-MS-2 (HS) & 132 & $5.15 \pm 0.19$ & $6.81 \pm 3.12$ & $105 \pm 75$ \\
\hline PTR-MS-1 (SS) & 132 & $3.12 \pm 0.13$ & $27.05 \pm 2.16$ & $2266 \pm 395$ \\
PTR-MS-1 (SS) Dry & 132 & $3.61 \pm 0.15$ & $2.14 \pm 2.92$ & $1306 \pm 396$ \\
\hline PTR-MS-1 (HS) & 88 & $1.65 \pm 0.11$ & $15.96 \pm 9.08$ & $55299 \pm 9365$ \\
PTR-MS-1 (HS) & 95 & $1.36 \pm 0.20$ & $5.28 \pm 16.42$ & $6632 \pm 3526$ \\
PTR-MS-1 (HS) & 106 & $1.37 \pm 0.19$ & $1.39 \pm 5.87$ & $674 \pm 566$ \\
PTR-MS-1 (HS) & 116 & $1.05 \pm 0.38$ & $0.27 \pm 1.22$ & $52 \pm 47$ \\
PTR-MS-1 (HS) & 132 & $1.08 \pm 0.13$ & $0.05 \pm 0.10$ & $3 \pm 8$ \\
\hline
\end{tabular}

a voltage of $600 \mathrm{~V}$, yielding a corresponding field strength of $132 \mathrm{Td}$. To ensure that products from the reaction between $\mathrm{O}_{2}^{+}$and acetic acid did not bias results, the ion source was optimized such that $\mathrm{O}_{2}^{+}$was less than $1 \%$ of the $\mathrm{H}_{3} \mathrm{O}^{+}$ signal. The primary ion signal $\left(\mathrm{H}_{3} \mathrm{O}^{+}\right)$in PTR-MS-1 (SS) was $3 \times 10^{6} \mathrm{hz}$, in PTR-MS-1 (HS) was $1-2 \times 10^{6} \mathrm{~Hz}$, and was $5 \times 10^{6} \mathrm{~Hz}$ in PTR-MS-2 (HS). (The lower ion signal in PTR-MS-1 (HS) is attributed to the smaller amount of water vapor present in the ion source as a result of modification.) The signals for $\mathrm{H}_{3} \mathrm{O}^{+}(m / z 19), \mathrm{H}_{3} \mathrm{O}^{+}\left(\mathrm{H}_{2} \mathrm{O}\right)(m / z, 37)$ and $\mathrm{H}_{3} \mathrm{O}^{+}\left(\mathrm{H}_{2} \mathrm{O}\right)_{2}(\mathrm{~m} / \mathrm{z} 55)$ for all calibration experiments (Table 2) indicate that each instrument allowed different amounts of water vapor into the drift tube from the ion source, corresponding to differing abundances of protonated clusters. The ratios of each hydrated cluster to $m / z, 19$ are given in Table 2 . The ion signals are presented as measured, and no correction was made for transmission losses. The background signals at $m / z 61$ and $m / z 43$ were less than 11 normalized counts per second (ncps).

The sensitivity of the PTR-MS to acetic acid is expressed in terms of the calibration factor via

$$
\frac{\mathrm{ncps}}{\mathrm{ppbv}}=\frac{m / z 61}{\mathrm{H}_{3} \mathrm{O}^{+} \cdot[\text { Acetic Acid }]} \times 10^{6}
$$

where the calibration factor is defined as the signal $(\mathrm{Hz}$ at $\mathrm{m} / \mathrm{z} 61$ for every ppbv acetic acid) normalized to the primary ion signal $\left(\mathrm{H}_{3} \mathrm{O}^{+}, \mathrm{Hz}\right.$ at $\left.\mathrm{m} / z \mathrm{19}\right)$, and scaled by $10^{6}$ (Warneke et al., 2001).

\subsection{Permeation system}

The instruments were calibrated via dilution and analysis of acetic acid from a permeation source (Talbot et al., 1999). A free-flowing calibration manifold was constructed such that acetic acid was exposed to only inert glass, passivated stainless steel, and Teflon surfaces thereby minimizing hysteresis problems associated with active surfaces and dead volume. The insulated permeation oven was controlled by a thermo- stat and embedded in a large thermal block to buffer it against variations in room temperature and cycling of the heating elements. Purified air was generated by passing ambient air over Pd-on-alumina $(0.5 \%)$ bead-filled catalytic converter (Apel-Riemer Environmental) operating at $425^{\circ} \mathrm{C}$. This purification technique removed hydrocarbons and other reactive impurities from air without altering major constituents including water vapor and $\mathrm{CO}_{2}$. The flow of purified air was then split into two channels, which were controlled by mass flow controllers (MKS Instruments). Both flows were controlled upstream of the permeation oven to avoid exposing the wetted surfaces in the controllers to acetic acid. A constant permeation flow $\left(F_{\text {perm }}\right)$ of $100( \pm 5 \%) \mathrm{cm}^{3} \mathrm{~min}^{-1}$ was directed to the permeation oven through $0.62 \mathrm{~cm}$ OD $\left(1 / 4^{\prime \prime}\right) / 0.47 \mathrm{~cm}$ ID Teflon tubing. The second purified air channel was a variable dilution $\left(F_{\text {dil }}\right)$ flow that ranged between 0 and $7000( \pm 5 \%) \mathrm{cm}^{3} \mathrm{~min}^{-1}$. The dilution flow was mixed with the permeation flow at a T-union, forming a combined flow $\left(F_{\text {perm }}+F_{\text {dil }}\right)$ that was sampled $61 \mathrm{~cm}$ downstream by the PTR-MS. A length of tubing extended beyond the PTR-MS inlet to prevent lab air from mixing into the system. The total length of the transfer lines after the permeation oven was limited to one meter to prevent back pressure from developing in the permeation oven, which would increase the emission rate of the permeation tube. Known mixing ratios of acetic acid were generated by diluting pure acetic acid emitted from a permeation tube (Kin-Tek Inc.) that was gravimetrically certified $\left(103 \pm 5 \% \mathrm{ng} \mathrm{min}^{-1}\right.$ at $\left.30^{\circ} \mathrm{C}\right)$ by the manufacturer. The high dilution flow rates yielded stable acetic acid calibration gas streams at low ppbv levels, within the range of those in ambient air, and much less than ppmv level standards typically generated by other techniques (Veres et al., 2010).

The dilution flow $\left(F_{\text {dil }}\right)$ was used to control the mixing ratio of acetic acid in the calibration gas. A typical calibration curve is displayed in Fig. 1a. The mixing ratios of acetic acid measured in each curve $( \pm 1 \sigma)$ were $8.4 \pm 0.8$, $13.8 \pm 1.4,20.4 \pm 2.0$, and $26.8 \pm 2.7 \mathrm{ppbv}$. As a check for 

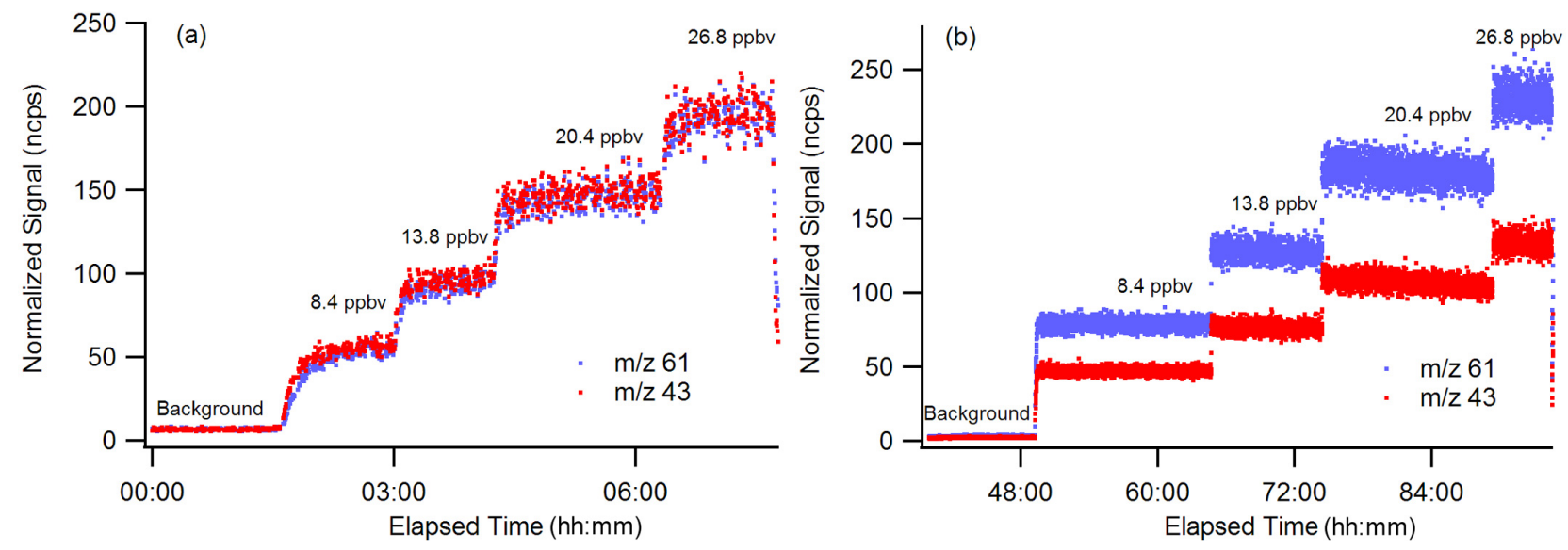

Fig. 1. Calibration curves for acetic acid obtained with the instruments used in this study: (a) PTR-MS-1 (SS) and (b) PTR-MS-2 (HS).

outside contaminants, a mass spectrum collected between $m / z 33$ and $m / z 99$ was scanned every 20 measurement cycles.

\subsection{Acetic acid measurements during the International Consortium for Atmospheric Research on Trans- port and Transformation (ICARTT) campaign}

From 2 July to 13 August 2004, the PTR-MS-2 (HS) was deployed on Appledore Island, ME, located $11 \mathrm{~km}$ off the coast $\left(42.97^{\circ} \mathrm{N}, 70.62^{\circ} \mathrm{W}\right)$ as part of the ICARTT campaign (Fehsenfeld et al., 2006). Ambient air was drawn from the top of a $20 \mathrm{~m}$ tower through a 30.5 -m-long, $9.53 \mathrm{~mm}$ ID PFA Teflon tube, with a flow rate of $\approx 751 \mathrm{~min}^{-1}$. A membrane pump was used to draw a sub-stream of air from the main inlet line at a flow rate of $11 \mathrm{~min}^{-1}$, from which the PTRMS sampled. The PTR-MS was operated using a drift tube pressure of $2.0 \mathrm{mbar}$ and voltage of $600 \mathrm{~V}(132 \mathrm{Td})$, settings identical to those used during the calibration experiments (Sect. 3.1). A total of 25 mass channels corresponding to various VOCs of interest were measured with dwell times between 5-20 s. Every $2.5 \mathrm{~h}$, the PTR-MS control software automatically switched the sample flow through a $13-\mathrm{cm}-\mathrm{long}$, $1.27 \mathrm{~cm}$ ID $0.5 \%$ Pd-on-alumina bead catalytic converter at $450{ }^{\circ} \mathrm{C}$ for $30 \mathrm{~min}$. The catalytic converter oxidized VOCs in the sample stream to provide a measurement of the instruments background signal (Ambrose et al., 2007). Based on the counting statistics of ambient and background signals, the average uncertainty of the PTR-MS measurements was 9.2\% $( \pm 1 \sigma)$ using the method described in Hayward et al. (2002).

To ascertain the accuracy of the PTR-MS acetic acid measurements, they were compared with co-located acetic acid measurements over 2 -h intervals by a tandem mist chamberion chromatographic technique (MC/IC) (Keene et al., 2004; Keene et al., 2007). Briefly, for the MC/IC measurements, ambient air was sampled at nominal flow rates of $201 \mathrm{~min}^{-1}$ through a size fractionating inlet and an inline Teflon filter to remove super- and sub- $\mu$ m-diameter particles, respectively, followed by tandem mist chambers containing deionized water. Exposed mist solutions were analyzed on site via ion chromatography. The average detection limited calculated following Keene et al. (1989) was $0.003 \mathrm{ppbv}$, and the average precision was $\pm 10 \%$ or \pm 0.002 ppbv, whichever corresponded to the higher absolute value (Keene et al., 1989). PTR-MS measurements were averaged over the 2-h sampling interval of the MC/IC (Fig. 2).

\section{Results and discussion}

\subsection{PTR-MS calibrations at 132 Td}

The calibration factors for PTR-MS-1 (SS), PTR-MS-2 (HS), and PTR-MS-1 (HS) at $132 \mathrm{Td}$ ranged from $7.0 \pm 0.3$ to $10.9 \pm 0.7 \mathrm{ncps} \mathrm{ppv}^{-1}$ with the standard sensitivity configuration having the smallest calibration factor and the modified high sensitivity configuration PTR-MS-1 (HS) having the largest (Table 1). At a dwell time of $5 \mathrm{~s}$, these calibration factors correspond to detection limits $(2 \sigma)$ of $0.06 \mathrm{ppbv}$ for (PTR-MS-2 (HS)), $0.16 \mathrm{ppbv}$ for PTR-MS-1 (SS), and $0.32 \mathrm{ppbv}$ for PTR-MS-1 (HS), assuming no losses in the sampling manifold. The higher detection limit found for PTR-MS-1 in the HS configuration is due to lower primary ion intensity compared to the other configurations tested, resulting in fewer target ions produced and detected. The calibration factor for PTR-MS-1 (SS) is $\sim 1 \mathrm{ncps} \mathrm{ppbv}^{-1}$ smaller than the value of $8.0 \pm 0.47 \mathrm{ncpspbv}^{-1}$ found for a different standard sensitivity PTR-MS in a previous study (de Gouw et al., 2003). The ratio of $m / z 61$ to $m / z 43$ indicates the degree of fragmentation of protonated acetic acid into the acylium ion $(\mathrm{m} / \mathrm{z}, 43)$ (Table 1 and Table 3$)$. The fragmentation was the greatest in PTR-MS-1 (SS), with a $m / z 61$ to $m / z 43$ ratio of 0.86 and the least in PTR-MS-1 (HS) with a ratio of 1.9. The total calibration factor, derived using the sum of $m / z 61+m / z 43$, was the greatest in 


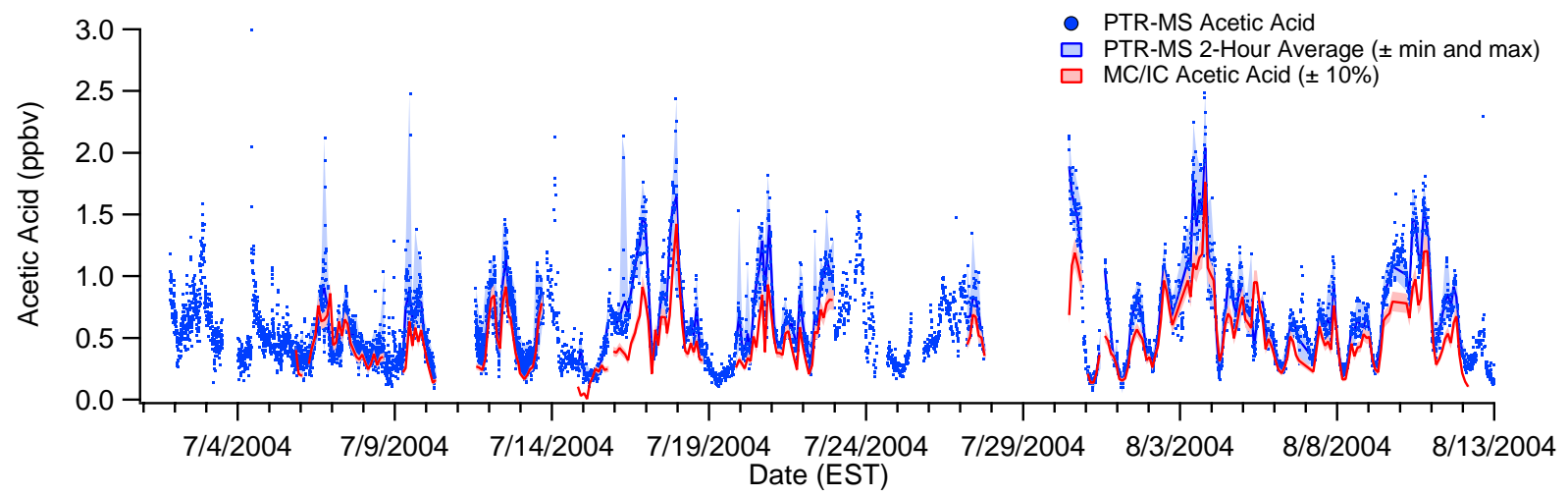

Fig. 2. Measurements of acetic acid from the PTR-MS (blue) and MC/IC (red) during ICARTT. For the periods when both techniques were operational, the PTR-MS average mixing ratios over the 2-h MC/IC sampling interval are depicted on the dark blue line with the corresponding individual values as dark blue dots. The range of PTR-MS measurements over each 2-h interval is light blue. The MC/IC average relative uncertainty $( \pm 10 \%)$ is shown in pink shading.

PTR-MS-1 (HS) with a value of $15.8 \pm 0.8 \mathrm{ncpspbv}^{-1}$, and the least with PTR-MS-2 (HS) with $13.4 \pm 0.4$ ncps ppbv $^{-1}$ (PTR-MS-1 (SS) yielded $14.0 \pm 0.4 \mathrm{ncps} \mathrm{ppbv}^{-1}$ ). This indicates that PTR-MS-2 was not as efficient at delivering product ions to the detector as PTR-MS-1.

The PTR-MS instruments responded quickly to changes in the acetic acid mixing ratio. PTR-MS-2 (HS) exhibited a nearly instantaneous response to mixing ratio changes, which were on the order of a few seconds (Fig. 1). PTRMS-1 exhibited rise times (time to $90 \%$ of full signal) that varied from $15 \mathrm{~min}$ to $48 \mathrm{~min}\left(0.4-0.2 \mathrm{ppbv} \mathrm{min}^{-1}\right)$ with the faster changes occurring at higher mixing ratios (Fig. 1); fall times from the highest mixing ratio were around $35 \mathrm{~min}\left(0.7 \mathrm{ppbv} \mathrm{min}^{-1}\right)$. The different response times are attributable to the vacuum isolation valves that were installed to protect the instruments during power failures. PTR-MS2 (HS) used a small diameter $(3.75 \mathrm{~mm})$ valve and tubing throughout the inlet system, while PTR-MS-1 had un-swept volume within a $6.35 \mathrm{~mm}$ valve and an $\sim 8 \mathrm{~cm}$ section of tubing that was attached to the $3.75 \mathrm{~mm}$ inlet.

\subsection{Calibration factor dependence on drift tube field strength}

PTR-MS-1 (HS) was calibrated over a range of drift tube conditions to explore the relationship between the field strength and the calibration factor for acetic acid. By reducing the field strength, the residence time of $\mathrm{H}_{3} \mathrm{O}^{+}$in the drift tube is increased, increasing product ion formation. Lower field strengths also decrease the energy of ionmolecule collisions, reducing fragmentation, but allowing the formation of protonated clusters (particularly with water) that do not readily engage in proton transfer reactions with some compounds. This effect can complicate the obtained spectra and introduce numerous challenges to accurate quantification compared to situations where $\mathrm{H}_{3} \mathrm{O}^{+}$is the
Table 3. Cluster and fragment distribution data obtained over a range of $E / N$ values with PTR-MS-1 (HS).

\begin{tabular}{lcccr}
\hline$E / N(\mathrm{Td})$ & $\begin{array}{c}\text { Ratio of } \\
(m / z 61)^{\mathrm{a}} / \\
(m / z 43)\end{array}$ & $\begin{array}{r}\text { Fraction } \\
m / z 43^{\mathrm{b}}\end{array}$ & $\begin{array}{r}\text { Fraction } \\
m / z 61^{\mathrm{b}}\end{array}$ & $\begin{array}{r}\text { Fraction } \\
m / z 79^{\mathrm{b}, \mathrm{c}}\end{array}$ \\
& & & & \\
\hline PTR-MS-1 (HS) & & & & \\
88 & 5.96 & 0.12 & 0.86 & $3.0 \times 10^{-2}$ \\
95 & 4.48 & 0.15 & 0.85 & $1.0 \times 10^{-2}$ \\
106 & 3.66 & 0.18 & 0.82 & 0.00 \\
116 & 2.89 & 0.23 & 0.77 & 0.00 \\
132 & 1.94 & 0.30 & 0.70 & 0.00 \\
PTR-MS-1 (SS) & & & & \\
132 & 0.86 & 0.53 & 0.46 & $5.0 \times 10^{-3}$ \\
132 (Dry) & 1.05 & 0.49 & 0.51 & 0.00 \\
PTR-MS-2 (HS) & & & & \\
132 & 1.47 & 0.40 & 0.60 & 0.00 \\
\hline
\end{tabular}

${ }^{a}$ Fragmentation ratio of protonated acetic acid to the acylium ion.

${ }^{\mathrm{b}}$ Fractional strength of each ion in the acetic acid signal at each $E / N$.

${ }^{c}$ Presumed $\mathrm{CH}_{3} \mathrm{COOH}_{2}\left(\mathrm{H}_{2} \mathrm{O}\right)^{+}$.

dominant reagent ion, offsetting the gains made in sensitivity to acetic acid.

During the field strength studies, the drift tube was maintained at $2.0 \mathrm{mbar}$ and $45^{\circ} \mathrm{C}$. At each calibration level, the drift tube was stepped through the following voltages: 400 , $433,481,530$, and $600 \mathrm{~V}$, corresponding to field strengths of $88,95,106,116$, and $132 \mathrm{Td}$.

The average $\mathrm{H}_{3} \mathrm{O}^{+}$signal was $1.1-1.8 \mathrm{MHz}$ for all field strengths (Table 2). At $132 \mathrm{Td}$, the ratio of $\mathrm{m} / \mathrm{z} 37$ to $\mathrm{m} / \mathrm{z} 19$ was $4.67 \times 10^{-3}$, and the ratio of $\mathrm{m} / z 55$ to $\mathrm{m} / z 19$ was $3.0 \times 10^{-6}$. At the lowest field strength $(88 \mathrm{Td})$, the ratio of $\mathrm{m} / \mathrm{z} 37$ to $\mathrm{m} / \mathrm{z} 19$ increased to $9.69 \times 10^{-1}$ and the ratio of $m / z 55$ to $m / z .19$ was $3.34 \times 10^{-2}$ (Table 3). The sensitivity to acetic acid was inversely proportional to field strength, following the trend noted by Wyche et al. (2009). At $132 \mathrm{Td}$, the calibration factor for $m / z 61$ was 
$10.9 \pm 0.7 \mathrm{ncpspbv}^{-1}$, while at a field strength of $88 \mathrm{Td}$ it was $30.8 \pm 2.6 \mathrm{ncps} \mathrm{ppbv}^{-1}$. The increase in this calibration factor at lower field strengths is due both to the increased reaction time, and the increased importance of proton transfer and ligand switching reactions from protonated water clusters in the drift tube.

Acetic acid fragmentation increases at higher field strengths and, hence, greater collision energies. The ratio of $m / z 61$ to $m / z 43$ was 5.96 at $88 \mathrm{Td}$ and decreased to 1.94 at $132 \mathrm{Td}$.

\subsection{Sensitivity dependence on sample air humidity}

The available literature regarding the sensitivity dependence on humidity for acetic acid is conflicting. This is important to consider since the humidity of ambient air is variable, and hence could impact the accuracy of measurements if unaccounted for. Warneke et al. (2001) found no relationship between humidity and sensitivity, while, subsequent to our experiments, Feilberg et al. (2010) found a very strong dependence for fragmentation, with the ratio of $m / z 61$ to $m / z 43$ ranging from 2.5 (0\% RH) to $0.9(80 \%$ $\mathrm{RH})$. In our study a separate calibration was done on PTRMS-1 (SS) using desiccant dried air. The calibration factors for $m / z 61$ and $m / z 43$ were $6.9 \pm 0.3 \mathrm{ncpsppbv}^{-1}$ and $5.6 \pm 0.3 \mathrm{ncps} \mathrm{ppbv}^{-1}$, respectively. The calibration factor at $\mathrm{m} / \mathrm{z} 61$ was within the uncertainty of the calibration factor obtained at ambient humidities, but at $m / z 43$ it was lower by $1.4 \mathrm{ncpsppbv}^{-1}$. The fragmentation ratio of $m / z 61$ to $m / z 43$ was 1.05 , greater than that obtained with ambient air (Table 3). The characteristics of reducing the amount of ambient water in the drift tube were decreased fragmentation coupled with somewhat lower ionization efficiency of acetic acid. However, the overall calibration factor did not change significantly from that at ambient humidity, consistent with the result from Warneke et al. (2001).

In contrast, across the different PTR-MS instruments, the amount of acetic acid fragmentation was proportional to the signal at $m / z 37\left(\mathrm{H}_{3} \mathrm{O}^{+} \cdot \mathrm{H}_{2} \mathrm{O}\right)$. PTR-MS-1 (HS) had the lowest fraction of $m / z 37$ and the least amount of fragmentation, while PTR-MS-1 (SS) had the largest fraction of $m / z 37$ and the most fragmentation (Table 3). As the relative strength of the signal at $m / z 37$ to $m / z 19$ is a proxy for the amount of water vapor in the PTR-MS drift tube (Warneke et al., 2001; Tani et al., 2004), this finding shows that fragmentation is also dependent on the amount water vapor in the drift tube, consistent with the findings of Feilberg et al. (2010).

Comparing across the different studies, high levels of water vapor in the drift tube from the ion source make the humidity contributions from ambient air minor, yielding calibration results that are humidity independent. In situations where water vapor from the ion source is reduced, the role of ambient humidity in drift tube water vapor levels will be significant, giving a humidity-dependent instrument response.

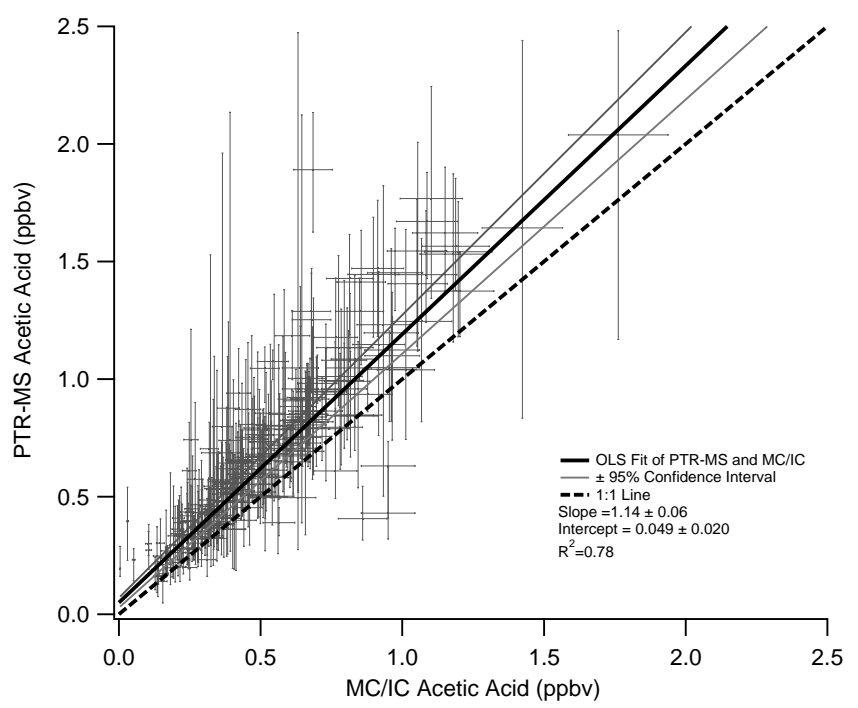

Fig. 3. Scatter plot of PTR-MS versus MC/IC measurements of acetic acid on Appledore Island during the ICARTT campaign. The error bars reflect the uncertainty of the individual PTR-MS and $\mathrm{MC} / \mathrm{IC}$ measurements.

A weak signal at $m / z 79$ was present at field strengths of $88 \mathrm{Td}$ and $95 \mathrm{Td}$, but was not detectable at higher field strengths in PTR-MS-1 (HS). A small signal was present in the full mass spectrum of PTR-MS-1 (SS) as well, but not during calibrations using dry air. The signal at $\mathrm{m} / z 79$ is likely to be the hydrated acetic acid cluster $\left[\mathrm{CH}_{3} \mathrm{COOH}_{2}^{+}\left(\mathrm{H}_{2} \mathrm{O}\right)\right]$, formed through a ligand switching reaction with $\mathrm{H}_{3} \mathrm{O}^{+}\left(\mathrm{H}_{2} \mathrm{O}\right)$. Hartungen et al. (2004) detected the presence of $m / z 79$ in their standard sensitivity PTR-MS (comprising $3.7 \%$ of the total acetic acid signal), which was enhanced by the high ambient humidities present in their experiments. It is likely that the hydrated acetic acid clusters undergo collision induced dissociation subsequent to their formation, explaining why the signal at $m / z 79$ was very small (Mackay et al., 1978; Hartungen et al., 2004).

\subsection{PTR-MS and MC/IC intercomparison on Appledore Island during ICARTT 2004}

The performance of the PTR-MS for measuring ambient acetic acid was evaluated further via direct intercomparison with paired MC/IC measurements (Fig. 2). A weighted orthogonal least squares regression (OLS) (Boggs et al., 1989) of the acetic acid data from the PTR-MS and MC/IC measurements is shown in Fig. 3. The resulting slope of the two datasets $(N=271)$ yielded a slope of $1.14 \pm 0.06(2 \sigma)$, an intercept of $0.049 \pm 0.020 \mathrm{ppbv}(2 \sigma$; statistically significant), and a correlation coefficient $\left(R^{2}\right)$ of 0.78 .

Agreement between results for the two measurement techniques was probably impacted by two factors involving the performance of the PTR-MS. Unplanned electrical power failures occurred frequently during the campaign. When 


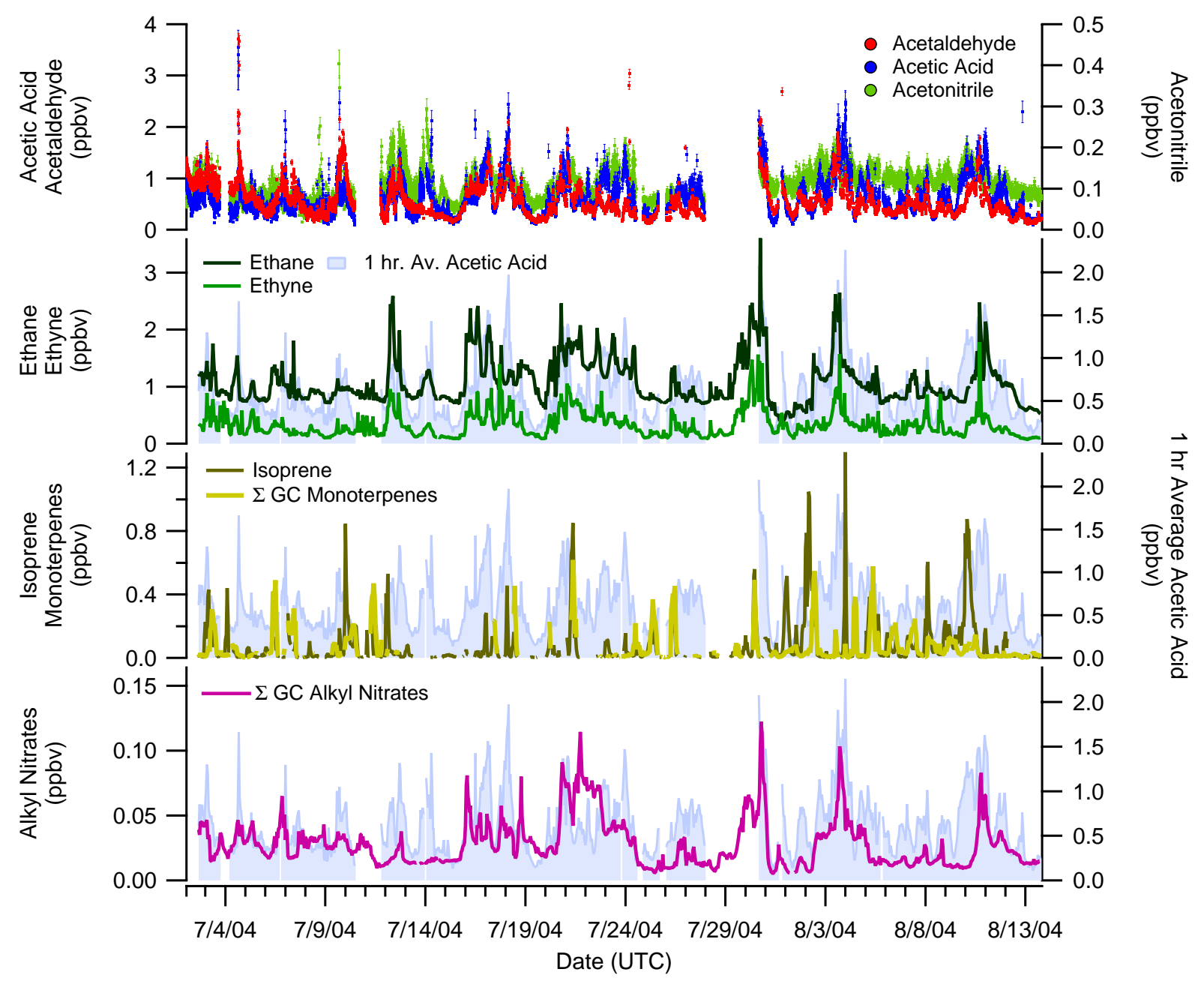

Fig. 4. The different primary and secondary sources of acetic acid are reflected in relationships with anthropogenic emissions (acetaldehyde (PTR-MS), ethane (GC) and ethyne (GC)), biogenic compounds (isoprene (GC), monoterpenes (sum of $\alpha$ - and $\beta$-pinene, camphene, and limonene; GC), biomass burning (acetonitrile (PTR-MS)), and photochemical production (sum of methyl-, ethyl-, butyl-, propyl-, 2-, and 3-pentyl nitrates (GC)).

power was interrupted, ambient air entered the vacuum system, after which several days were required to fully desorb compounds from instrument surfaces. These outages contributed to the variability in the background signal, causing it to be elevated for periods of up to several days. In addition, at the time of the campaign, the PTR-MS was also relatively new, having only been used a few months, and consequently wetted surfaces within the instrument. Particularly the Teflon spacers in the drift tube and other polymer seals in the instrument may not have been passivated. Both factors contributed to the observed temporal variability of the PTR-MS background signal during the campaign, which are likely to contribute to the non-unity slope of the correlation with the MC/IC measurements. It also is possible that that another compound (or set of compounds) with a similar temporal variation to acetic acid contributed a small interference at $m / z 61$. However, the performance issues introduced by the frequent power outages make the degree of interference hard to quantify.

Comparing the individual PTR-MS measurements with the 2-h average from the MC/IC (Fig. 2) shows many short timescale events that are resolved by the PTR-MS. There are several events that are fast enough to either be unresolved by the MC/IC or are represented by a single data point. That the PTR-MS was able to capture the full range and temporal variability of acetic acid demonstrates the strength of the technique.

During the ICARTT campaign the PTR-MS made 6626 individual acetic acid measurements. The average ( \pm 1 standard deviation $)$ and the median $( \pm 9.2 \%$ measurement uncertainty) mixing ratio of PTR-MS measured acetic acid were $0.608 \pm 0.342(1 \sigma) \mathrm{ppbv}$ and $0.530 \pm 0.049 \mathrm{ppbv}$, respectively. The mixing ratios ranged from $0.075 \pm 0.007 \mathrm{ppbv}$ to $3.555 \pm 0.327$ ppbv (Fig. 4). 
Large-scale atmospheric transport from distinct source regions significantly influences air quality in coastal New England. Air masses transported along the heavily populated mid-Atlantic corridor are highly enriched in pollutants, such as ozone, carbon monoxide, non-methane hydrocarbons, and halocarbons, relative to air masses transported from other regions (Mao and Talbot, 2004a, b; Angevine et al., 2004; Fischer et al., 2006; Chen et al., 2007; Darby et al., 2007; White et al., 2007). Relative temporal variability in acetic acid often correlated with tracers of anthropogenic activities, biomass burning, photochemical processing (Fig. 4), and it was generally elevated when terrestrially sourced air masses passed over Appledore (Haase, 2010). In the dataset for the campaign, acetic acid mixing ratios showed positive correlations with acetaldehyde $\left(R^{2}=0.35\right)$, ethane $\left(R^{2}=\right.$ $0.28)$, and ethyne $\left(R^{2}=0.35\right)$, compounds that are associated with mobile sources (Seinfeld and Pandis, 1998; Watson et al., 2001). Acetic acid levels also showed enhancements when acetonitrile $\left(R^{2}=0.35\right)$, a tracer for biomass burning, was elevated, linking acetic acid this combustion source (de Gouw et al., 2006; Talbot et al., 2011). Hourly average of acetic acid was also elevated when mixing ratios of the alkyl nitrates were correspondingly elevated. Alkyl nitrates are secondary products of hydrocarbon oxidation, and their presence could be taken as an indicator of photochemically produced acetic acid in polluted air masses. Acetic acid did not show correlation with the biogenic isoprene $\left(R^{2}=0.02\right)$ and monoterpene $\left(R^{2}=0.06\right)$ compounds. The levels of these compounds were low compared to terrestrial observations owing to photochemical processing before arrival at Appledore Island, so they are not necessarily robust tracers of biogenic emissions of acetic acid. These results have revealed that local levels of acetic acid in New England are controlled by a complex group of sources and processes and are not dominated by a single pathway, clearly warranting further investigation.

\section{Conclusions}

PTR-MS is a valuable technique for measuring an array of atmospheric VOCs, providing high time resolution, high sensitivity, and online analysis. By using a permeation tube based calibration source and high flow rates of dilution gas in a low back-pressure mixing system, it is possible to calibrate the PTR-MS at low ppbv mixing ratios for acetic acid. Our calibrations and others reported in the literature show that acetic acid fragments to varying degrees in different PTRMS systems. Fragmentation may be mediated by the amount of water vapor available in the drift tube, as fragmentation increases in instruments that have lower ion source skimmer pumping capacities. The difference in fragmentation ratios between different instruments emphasizes the importance of parameterizing each instrument's performance, as fragmentation of acetic acid is not precisely reproducible from one system to another. At $132 \mathrm{Td}$, we obtain calibration factors that vary between 7.0 and $10.9 \mathrm{ncps}$ for this compound.

During the ICARTT campaign, we measured acetic acid on Appledore Island with a PTR-MS and a MC/IC system operating in parallel at the same location. A regression of the PTR-MS averaged over the MC/IC sampling intervals yielded a slope of 1.14 , an intercept of $0.049 \mathrm{ppbv}$, and an $R^{2}$ of 0.78 . Frequent power outages during the campaign negatively impacted performance of the PTR-MS via associated increases in background variability. However, results suggest minor to negligible interferences by other compounds; the dominant signal is acetic acid. Our results indicate that PTRMS can reliably quantify acetic acid in coastal New England air, but additional work is recommended to characterize potential chemical interferences in other environments.

Acknowledgements. Financial support for this work was provided by the Office of Oceanic and Atmospheric Research at the National Oceanic and Atmospheric Administration under grants NA04OAR4600154 and NA05OAR4601080 to the University of New Hampshire and by the National Science Foundation through awards to the University of Virginia (ATM 0401628) and the University of New Hampshire (ATM 0401622). We thank L. C. Nielson, E. Fitz, T. Hagan, K. Garrison, K. Carpenter, Y. Zhou, R. Russo, J. Ambrose, M. White, H. Mao, E. Fischer, J. Maben, A. Smith, and others who have contributed to the measurements and management of the extensive AIRMAP database. We would like to thank Kevan Wyche and Paul Monks from the University of Leicester for providing detailed information about the response of their CIR-TOF-MS instrument to acetic acid. We would also like to thank Anita Lee of the US EPA, and Carsten Warneke of NOAA for providing clarification on their acetic acid calibration techniques. The US Geological Survey provided support while this manuscript was being prepared.

Any use of trade, product, or firm names is for descriptive purposes only and does not imply endorsement by the US Government.

Edited by: D. Heard

\section{References}

Ambrose, J. L., Mao, H., Mayne, H. R., Stutz, J., Talbot, R., and Sive, B. C.: Nighttime nitrate radical chemistry at Appledore Island, Maine during the 2004 International Consortium for Atmospheric Research on Transport and Transformation, J. Geophys. Res., 112, D21302, doi:10.1029/2007jd008756, 2007.

Ambrose, J. L., Haase, K., Russo, R. S., Zhou, Y., White, M. L., Frinak, E. K., Jordan, C., Mayne, H. R., Talbot, R., and Sive, B. C.: A comparison of GC-FID and PTR-MS toluene measurements in ambient air under conditions of enhanced monoterpene loading, Atmos. Meas. Tech., 3, 959-980, doi:10.5194/amt-3959-2010, 2010.

Angevine, W. M., Senff, C. J., White, A. B., Williams, E. J., Koermer, J., Miller, S. T. K., Talbot, R., Johnston, P. E., McKeen, S. A., and Downs, T.: Coastal Boundary Layer Influence on Pollutant Transport in New England, J. Appl. Meteorol., 43, 1425$1437,2004$. 
Blake, R. S., Monks, P. S., and Ellis, A. M.: Proton Transfer Reaction Mass Spectrometry, Chem. Rev., 109, 861-896, doi:10.1021/cr800364q, 2009.

Boggs, P. T., Donaldson, J. R., Byrd, R. H., and Schnabel, R. B.: Algorithm 676: ODRPACK: software for weighted orthogonal distance regression, ACM Trans. Math. Softw., 15, 348-364, doi:10.1145/76909.76913, 1989.

Cappellin, L., Karl, T., Probst, M., Ismailova, O., Winkler, P. M., Soukoulis, C., Aprea, E., Märk, T. D., Gasperi, F., and Biasioli, F.: On Quantitative Determination of Volatile Organic Compound Concentrations Using Proton Transfer Reaction Time-ofFlight Mass Spectrometry, Environ. Sci. Technol., 46, 22832290, doi:10.1021/es203985t, 2012.

Chebbi, A. and Carlier, P.: Carboxylic acids in the troposphere, occurrence, sources, and sinks: A review, Atmos. Environ., 30, 4233-4249, 1996.

Chen, M., Talbot, R., Mao, H., Sive, B., Chen, J., and Griffin, R. J.: Air mass classification in coastal New England and its relationship to meteorological conditions, J. Geophys. Res., 112, D10S05, doi:10.1029/2006jd007687, 2007.

Christian, T. J., Kleiss, B., Yokelson, R. J., Holzinger, R., Crutzen, P. J., Hao, W. M., Shirai, T., and Blake, D. R.: Comprehensive laboratory measurements of biomass-burning emissions: 2. First intercomparison of open-path FTIR, PTRMS, and GC-MS/FID/ECD, J. Geophys. Res., 109, D02311, doi:10.1029/2003jd003874, 2004.

Darby, L. S., McKeen, S. A., Senff, C. J., White, A. B., Banta, R. M., Post, M. J., Brewer, W. A., Marchbanks, R., Alvarez, R. J., II, Peckham, S. E., Mao, H., and Talbot, R.: Ozone differences between near-coastal and offshore sites in New England: Role of meteorology, J. Geophys. Res., 112, D16S91, doi:10.1029/2007jd008446, 2007.

de Gouw, J. and Warneke, C.: Measurements of Volatile Organic Compounds in the Earth's Atmosphere Using Proton-TransferReaction Mass Spectrometry, Mass Spectrom. Rev., 26, $223-$ 257, doi:10.1002/mas.20119, 2006.

de Gouw, J. A., Goldan, P. D., Warneke, C., Kuster, W. C., Roberts, J. M., Marchewka, M., Bertman, S. B., Pszenny, A. A. P., and Keene, W. C.: Validation of proton transfer reaction-mass spectrometry (PTR-MS) measurements of gas-phase organic compounds in the atmosphere during the New England Air Quality Study (NEAQS) in 2002, J. Geophys. Res., 108, 4682-4700, doi:10.1029/2003jd003863, 2003.

de Gouw, J. A., Warneke, C., Stohl, A., Wollny, A. G., Brock, C. A., Cooper, O. R., Holloway, J. S., Trainer, M., Fehsenfeld, F. C., Atlas, E. L., Donnelly, S. G., Stroud, V., and Lueb, A.: Volatile organic compounds composition of merged and aged forest fire plumes from Alaska and western Canada, J. Geophys. Res., 111, D10303, doi:10.1029/2005jd006175, 2006.

Fehsenfeld, F. C., Ancellet, G., Bates, T. S., Goldstein, A. H., Hardesty, R. M., Honrath, R., Law, K. S., Lewis, A. C., Leaitch, R., McKeen, S., Meagher, J., Parrish, D. D., Pszenny, A. A. P., Russell, P. B., Schlager, H., Seinfeld, J., Talbot, R., and Zbinden, R.: International Consortium for Atmospheric Research on Transport and Transformation (ICARTT): North America to Europe; Overview of the 2004 summer field study, J. Geophys. Res., 111, D23S01, doi:10.1029/2006jd007829, 2006.

Feilberg, A., Liu, D., Adamsen, A. P. S., Hansen, M. J., and Jonassen, K. E. N.: Odorant Emissions from Intensive
Pig Production Measured by Online Proton-Transfer-Reaction Mass Spectrometry, Environ. Sci. Technol., 44, 5894-5900, doi:10.1021/es100483s, 2010.

Fischer, E., Pszenny, A., Keene, W., Maben, J., Smith, A., Stohl, A., and Talbot, R.: Nitric acid phase partitioning and cycling in the New England coastal atmosphere, J. Geophys. Res., 111, D23S09, doi:10.1029/2006jd007328, 2006.

Fortner, E. C., Zheng, J., Zhang, R., Berk Knighton, W., Volkamer, R. M., Sheehy, P., Molina, L., and André, M.: Measurements of Volatile Organic Compounds Using Proton Transfer Reaction - Mass Spectrometry during the MILAGRO 2006 Campaign, Atmos. Chem. Phys., 9, 467-481, doi:10.5194/acp-9-467-2009, 2009.

Grosjean, E. and Grosjean, D.: The Reaction of Unsaturated Aliphatic Oxygenates with Ozone, J. Atmos. Chem., 32, 205232, 1999.

Haase, K. B.: Calibration, Optimization, and Deployment of PTRMS Instruments During the AIRMAP Project, Doctor of Philosophy, Chemistry, University of New Hampshire, Durham, 186 pp., 2010.

Hansel, A., Jordan, A., Holzinger, R., Prazeller, P., Vogel, W., and Lindinger, W.: Proton transfer reaction mass spectrometry: online trace of gas analysis at the ppb level, Int. J. Mass Spectrom. Ion Processes, 149-150, 609-619, 1995.

Hartungen, E. v., Wisthaler, A., Mikoviny, T., Jaksch, D., Boscaini, E., Dunphy, P. J., and Märk, T. D.: Proton-transfer-reaction mass spectrometry (PTR-MS) of carboxylic acids: Determination of Henry's law constants and axillary odour investigations, Int. J. Mass spectrom., 239, 243-248, 2004.

Hayward, S., Hewitt, C. N., Sartin, J. H., and Owen, S. M.: Performance Characteristics and Applications of a Proton Transfer Reaction-Mass Spectrometer for Measuring Volatile Organic Compounds in Ambient Air, Environ. Sci. Technol., 36, 15541560, doi:10.1021/es0102181, 2002.

Holzinger, R., Sandoval-Soto, L., Rottenberger, S., Crutzen, P. J., and Kesselmeier, J.: Emissions of volatile organic compounds from Quercus ilex L. measured by Proton Transfer Reaction Mass Spectrometry under different environmental conditions, J. Geophys. Res., 105, 20573-20579, doi:10.1029/2000jd900296, 2000.

Holzinger, R., Millet, D. B., Williams, B., Lee, A., Kreisberg, N., Hering, S. V., Jimenez, J., Allan, J. D., Worsnop, D. R., and Goldstein, A. H.: Emission, oxidation, and secondary organic aerosol formation of volatile organic compounds as observed at Chebogue Point, Nova Scotia, J. Geophys. Res., 112, D10S24, doi:10.1029/2006jd007599, 2007.

Ito, A., Sillman, S., and Penner, J. E.: Effects of additional nonmethane volatile organic compounds, organic nitrates, and direct emissions of oxygenated organic species on global tropospheric chemistry, J. Geophys. Res., 112, D06309, doi:10.1029/2005jd006556, 2007.

Jardine, K., Abrell, L., Kurc, S. A., Huxman, T., Ortega, J., and Guenther, A.: Volatile organic compound emissions from Larrea tridentata (creosotebush), Atmos. Chem. Phys., 10, 1219112206, doi:10.5194/acp-10-12191-2010, 2010.

Jobson, B. T., Alexander, M. L., Paupin, G. D., and Muntean, G. G.: Online-analysis of organic compounds in diesel exhuast using a proton transfer reaction mass spectrometer (PTR-MS), Int. J. Mass spectrom., 245, 78-89, doi:10.1016/j.ijms.2005.05.009, 
2005.

Karl, T., Potosnak, M., Guenther, A., Clark, D., Walker, J., Herrick, J. D., and Geron, C.: Exchange processes of volatile organic compounds above a tropical rain forest: Implications for modeling tropospheric chemistry above dense vegetation, J. Geophys. Res., 109, D18306, doi:10.1029/2004jd004738, 2004.

Karl, T., Harley, P., Guenther, A., Rasmussen, R., Baker, B., Jardine, K., and Nemitz, E.: The bi-directional exchange of oxygenated VOCs between a loblolly pine (Pinus taeda) plantation and the atmosphere, Atmos. Chem. Phys., 5, 3015-3031, doi:10.5194/acp-5-3015-2005, 2005.

Keene, W. C., Talbot, R. W., Andreae, M. O., Beecher, K., Berresheim, H., Castro, M., Farmer, J. C., Galloway, J. N., Hoffmann, M. R., Li, S.-M., Maben, J. R., Munger, J. W., Norton, R. B., Pszenny, A. A. P., Puxbaum, H., Westberg, H., and Winiwarter, W.: An Intercomparison of Measurement Systems for Vapor and Particulate Phase Concentrations of Formic and Acetic Acids, J. Geophys. Res., 94, 6457-6471, doi:10.1029/JD094iD05p06457, 1989.

Keene, W. C., Pszenny, A. A. P., Maben, J. R., Stevenson, E., and Wall, A.: Closure evaluation of size-resolved aerosol $\mathrm{pH}$ in the New England coastal atmosphere during summer, J. Geophys. Res., 109, D23307, doi:10.1029/2004jd004801, 2004.

Keene, W. C., Stutz, J., Pszenny, A. A. P., Maben, J. R., Fischer, E. V., Smith, A. M., von Glasow, R., Pechtl, S., Sive, B. C., and Varner, R. K.: Inorganic chlorine and bromine in coastal New England air during summer, J. Geophys. Res., 112, D10S12, doi:10.1029/2006jd007689, 2007.

Kesselmeier, J.: Exchange of Short-Chain Oxygenated Volatile Organic Compounds (VOCs) between Plants and the Atmosphere: A Compilation of Field and Laboratory Studies, J. Atmos. Chem., 39, 219-233, 2001.

Kim, S., Karl, T., Guenther, A., Tyndall, G., Orlando, J., Harley, P., Rasmussen, R., and Apel, E.: Emissions and ambient distributions of Biogenic Volatile Organic Compounds (BVOC) in a ponderosa pine ecosystem: interpretation of PTR-MS mass spectra, Atmos. Chem. Phys., 10, 1759-1771, doi:10.5194/acp-101759-2010, 2010.

Lee, A., Goldstein, A. H., Keywood, M. D., Gao, S., Varutbangkul, V., Bahreini, R., Ng, N. L., Flagan, R. C., and Seinfeld, J. H.: Gas-phase products and secondary aerosol yields from the ozonolysis of ten different terpenes, J. Geophys. Res., 111, D07302, doi:10.1029/2005jd006437, 2006a.

Lee, A., Goldstein, A. H., Kroll, J. H., Ng, N. L., Varutbangkul, V., Flagan, R. C., and Seinfeld, J. H.: Gas-phase products and secondary aerosol yields from the photooxidation of 16 different terpenes, J. Geophys. Res., 111, D17305, doi:10.1029/2006jd007050, 2006b.

Lindinger, W., Hansel, A., and Jordan, A.: Proton-transfer-reaction mass spectrometry (PTR-MS): on-line monitoring of volatile organic compounds at pptv levels, Chem. Soc.Rev., 27, 346-375, doi:10.1039/a827347z, 1998a.

Lindinger, W., Hansel, A., and Jordan, A.: On-line monitoring of volatile organic compounds at pptv levels by means of protontransfer-reaction mass spectrometry (PTR-MS) medical applications, food control and environmental research, Int. J. Mass Spectrom. Ion Processes, 173, 191-241, 1998b.

Mackay, G. I., Hopkinson, A. C., and Bohme, D. K.: Acid catalysis in the gas phase: dissociative proton transfer to formic and acetic acid, J. Am. Chem. Soc., 100, 7460-7464, doi:10.1021/ja00492a003, 1978.

Maleknia, S. D., Bell, T. L., and Adams, M. A.: PTR-MS analysis of reference and plant-emitted volatile organic compounds, Int. J. Mass spectrom., 262, 203-210, 2007.

Mao, H. and Talbot, R.: $\mathrm{O}_{3}$ and $\mathrm{CO}$ in New England: Temporal variations and relationships, J. Geophys. Res., 109, D21304, doi:10.1029/2004jd004913, 2004a.

Mao, H. and Talbot, R.: Role of meteorological processes in two New England ozone episodes during summer 2001, J. Geophys. Res., 109, D20305, doi:10.1029/2004jd004850, 2004 b.

Meng, Z., Seinfeld, J. H., and Saxena, P.: Gas/Aerosol Distribution of Formic and Acetic Acids, Aerosol Sci. Technol., 23, 561-578, 1995.

Niki, H., Maker, P. D., Savage, C. M., and Breitenbach, L. P.: FTIR study of the kinetics and mechanism for chlorine-atominitiated reactions of acetaldehyde, J. Phys. Chem., 89, 588-591, doi:10.1021/j100250a008, 1985.

Orzechowska, G. E. and Paulson, S. E.: Photochemical Sources of Organic Acids. 1. Reaction of Ozone with Isoprene, Propene, and 2-Butenes under Dry and Humid Conditions Using SPME, J. Phys. Chem. A, 109, 5358-5365, doi:10.1021/jp050166s, 2005.

Paulot, F., Wunch, D., Crounse, J. D., Toon, G. C., Millet, D. B., DeCarlo, P. F., Vigouroux, C., Deutscher, N. M., González Abad, G., Notholt, J., Warneke, T., Hannigan, J. W., Warneke, C., de Gouw, J. A., Dunlea, E. J., De Mazière, M., Griffith, D. W. T., Bernath, P., Jimenez, J. L., and Wennberg, P. O.: Importance of secondary sources in the atmospheric budgets of formic and acetic acids, Atmos. Chem. Phys., 11, 1989-2013, doi:10.5194/acp-11-1989-2011, 2011.

Rogers, T. M., Grimsrud, E. P., Herndon, S. C., Jayne, J. T., Kolb, C. E., Allwine, E., Westberg, H., Lamb, B. K., Zavala, M., Molina, L. T., Molina, M. J., and Knighton, W. B.: On-road measurements of volatile organic compounds in the Mexico City metropolitan area using proton transfer reaction mass spectrometry, Int. J. Mass spectrom., 252, 26-37, 2006.

Rosado-Reyes, C. M. and Francisco, J. S.: Atmospheric Oxidation Pathways of Acetic Acid, J. Phys. Chem. A, 110, 4419-4433, doi:10.1021/jp0567974, 2006.

Schwarz, K., Filipiak, W., and Amann, A.: Determining concentration patterns of volatile compounds in exhaled breath by PTR-MS, J. Breath Res., 3, 027002, doi:10.1088/17527155/3/2/027002, 2009.

Seinfeld, J. H. and Pandis, S. N.: Atmospheric Composition, Global Cycles, and Lifetimes, in: Atmos. Chem. Phys., 1st ed., John Wiley and Sons, Inc, New York, 49-124, 1998.

Sellegri, K., Umann, B., Hanke, M., and Arnold, F.: Deployment of a ground-based CIMS apparatus for the detection of organic gases in the boreal forest during the QUEST campaign, Atmos. Chem. Phys., 5, 357-372, doi:10.5194/acp-5-357-2005, 2005.

Spanel, P., Diskin, A. M., Wang, T., and Smith, D.: A SIFT study of the reactions of $\mathrm{H}_{3} \mathrm{O}^{+}$, $\mathrm{NO}^{+}$and $\mathrm{O}_{2}^{+}$with hydrogen peroxide and peroxyacetic acid, Int. J. Mass spectrom., 228, 269-283, 2003.

Steeghs, M., Bais, H. P., de Gouw, J., Goldan, P., Kuster, W., Northway, M., Fall, R., and Vivanco, J. M.: Proton-Transfer-Reaction Mass Spectrometry as a New Tool for Real Time Analysis of Root-Secreted Volatile Organic Compounds in Arabidopsis, Plant Physiol., 135, 47-58, doi:10.1104/pp.104.038703, 2004. 
Steinbacher, M., Dommen, J., Ammann, C., Spirig, C., Neftel, A., and Prevot, A. S. H.: Performance characteristics of a protontransfer-reaction mass spectrometer (PTR-MS) derived from laboratory and field measurements, Int. J. Mass spectrom., 219, 117-128, doi:10.1016/j.ijms.2004.07.015, 2004.

Talbot, R. W., Dibb, J. E., Scheuer, E. M., Blake, D. R., Blake, N. J., Gregory, G. L., Sachse, G. W., Bradshaw, J. D., Sandholm, S. T., and Singh, H. B.: Influence of biomass combustion emissions on the distribution of acidic trace gases over the southern Pacific basin during austral springtime, J. Geophys. Res., 104, 56235634, doi:10.1029/98jd00879, 1999.

Talbot, R., Mao, H., Feddersen, D., Smith, M., Kim, S. Y., Sive, B., Haase, K., Ambrose, J., Zhou, Y., and Russo, R.: Comparison of Particulate Mercury Measured with Manual and Automated Methods, Atmosphere, 2, 1-20, 2011.

Tani, A., Hayward, S., Hansel, A., and Hewitt, C. N.: Effect of water vapour pressure on monoterpene measurements using proton transfer reaction-mass spectrometry (PTR-MS), Int. J. Mass spectrom., 239, 161-169, 2004.

Veres, P., Gilman, J. B., Roberts, J. M., Kuster, W. C., Warneke, C., Burling, I. R., and de Gouw, J.: Development and validation of a portable gas phase standard generation and calibration system for volatile organic compounds, Atmos. Meas. Tech., 3, 683-691, doi:10.5194/amt-3-683-2010, 2010.

Vlasenko, A., Macdonald, A .M., Sjostedt, S. J., and Abbatt, J. P. D.: Formaldehyde measurements by Proton transfer reaction - Mass Spectrometry (PTR-MS): correction for humidity effects, Atmos. Meas. Tech., 3, 1055-1062, doi:10.5194/amt-3-1055-2010, 2010.

von Kuhlmann, R., Lawrence, M. G., Crutzen, P. J., and Rasch, P. J.: A model for studies of tropospheric ozone and nonmethane hydrocarbons: Model evaluation of ozone-related species, J. Geophys. Res., 108, 4729-4755, doi:10.1029/2002jd003348, 2003.

Warneke, C., Kuczynski, J., Hansel, A., Jordan, A., Vogel, W., and Lindinger, W.: Proton transfer reaction mass spectrometry (PTRMS): propanol in human breath, Int. J. Mass Spectrom. Ion Processes, 154, 61-70, 1996.

Warneke, C., van der Veen, C., Luxembourg, S., de Gouw, J. A., and Kok, A.: Measurements of benzene and toluene in ambient air using proton-transfer-reaction mass spectrometry: calibration, humidity dependence, and field intercomparison, Int. J. Mass spectrom., 207, 167-182, 2001.

Warneke, C., de Gouw, J. A., Kuster, W. C., Goldan, P. D., and Fall, R.: Validation of Atmospheric VOC Measurements by Proton-Transfer- Reaction Mass Spectrometry Using a GasChromatographic Preseparation Method, Environ. Sci. Technol., 37, 2494-2501, doi:10.1021/es026266i, 2003.
Warneke, C., de Gouw, J. A., Goldan, P. D., Kuster, W. C., Williams, E. J., Lerner, B. M., Jakoubek, R., Brown, S. S., Stark, H., Aldener, M., Ravishankara, A. R., Roberts, J. M., Marchewka, M., Bertman, S., Sueper, D. T., McKeen, S. A., Meagher, J. F., and Fehsenfeld, F. C.: Comparison of daytime and nighttime oxidation of biogenic and anthropogenic VOCs along the New England coast in summer during New England Air Quality Study 2002, J. Geophys. Res., 109, D10309, doi:10.1029/2003jd004424, 2004.

Watson, J. G., Chow, J. C., and Fujita, E. M.: Review of volatile organic compound source apportionment by chemical mass balance, Atmos. Environ., 35, 1567-1584, doi:10.1016/s13522310(00)00461-1, 2001.

White, A. B., Darby, L. S., Senff, C. J., King, C. W., Banta, R. M., Koermer, J., Wilczak, J. M., Neiman, P. J., Angevine, W. M., and Talbot, R.: Comparing the impact of meteorological variability on surface ozone during the NEAQS (2002) and ICARTT (2004) field campaigns, J. Geophys. Res., 112, D10S14, doi:10.1029/2006jd007590, 2007.

Williams, J., Pöschl, U., Crutzen, P. J., Hansel, A., Holzinger, R., Warneke, C., Lindinger, W., and Lelieveld, J.: An Atmospheric Chemistry Interpretation of Mass Scans Obtained from a Proton Transfer Mass Spectrometer Flown over the Tropical Rainforest of Surinam, J. Atmos. Chem., 38, 133-166, 2001.

Wisthaler, A., Apel, E. C., Bossmeyer, J., Hansel, A., Junkermann, W., Koppmann, R., Meier, R., Müller, K., Solomon, S. J., Steinbrecher, R., Tillmann, R., and Brauers, T.: Technical Note: Intercomparison of formaldehyde measurements at the atmosphere simulation chamber SAPHIR, Atmos. Chem. Phys., 8, 21892200, doi:10.5194/acp-8-2189-2008, 2008.

Wyche, K. P., Monks, P. S., Ellis, A. M., Cordell, R. L., Parker, A. E., Whyte, C., Metzger, A., Dommen, J., Duplissy, J., Prevot, A. S. H., Baltensperger, U., Rickard, A. R., and Wulfert, F.: Gas phase precursors to anthropogenic secondary aerosol: detailed observations of 1,3,5-trimethylbenzene photooxidation, Atmos. Chem. Phys., 9, 635-665, doi:10.5194/acp-9-635-2009, 2009.

Yu, Y., Ezell, M. J., Zelenyuk, A., Imre, D., Alexander, L., Ortega, J., D’Anna, B., Harmon, C. W., Johnson, S. N., and FinlaysonPitts, B. J.: Photooxidation of $\alpha$-pinene at high relative humidity in the presence of increasing concentrations of $\mathrm{NO}_{x}$, Atmos. Environ., 42, 5044-5060, 2008. 